九州大学学術情報リポジトリ

Kyushu University Institutional Repository

\title{
SC-associated Ionospheric Electric Fields at Low Latitude : FM-CW Radar Observation
}

Ikeda, Akihiro

Department of Earth and Planetary Sciences, Graduate School of Sciences, Kyushu University

Yumoto, Kiyofumi

Space Environment Research Center, Kyushu University

Shinohara, Manabu

Space Environment Research Center, Kyushu University

Nozaki, Kenro

National Institute of Information and Communications Technology

他

https://doi.org/10.5109/11811

出版情報：九州大学大学院理学研究院紀要：Series D, Earth and planetary sciences. 32 (1)，pp. 16, 2008-02-01. Faculty of Science, Kyushu University バージョン :

権利関係 : 
Mem. Fac. Sci., Kyushu Univ., Ser. D, Earth \& Planet. Sci., Vol. XXXII, No. 1, pp. 1-6, February 1, 2008

\title{
SC-associated Ionospheric Electric Fields at Low Latitude: FM-CW Radar Observation
}

\author{
Akihiro Ikeda*, Kiyohumi Yumoto**, Manabu Shinohara ${ }^{* *}$, \\ Kenro Nozaki $^{* * *}$, Akimasa Yoshikawa ${ }^{* * * *}$ and Atsuki Shinbori ${ }^{* * * *}$
}

\begin{abstract}
We present the low-latitude ionospheric electric field during the main impulse (MI) phase of two geomagnetic sudden commencements (SCs), observed for the first time by an FM-CW radar. From our observation, the direction of the ionospheric electric field is eastward in the daytime and westward in the nighttime sectors. This difference indicates the penetration of the dawn-to-dusk polar electric field associated with the SCs into the low-latitude ionosphere.
\end{abstract}

Keywords: ionosphere, ionospheric electric fields, HF radar, sudden commencement

\section{Introduction}

A sudden enhancement of the solar wind dynamic pressure due to the interplanetary shock or discontinuity causes an abrupt increase of the H-component of geomagnetic field especially at low and middle latitudes (e.g., Araki, 1994). This phenomenon is called geomagnetic sudden commencement (SC). Such a step-function like increase of the H-component is called main impulse (MI). Often the MI is preceded by a negative variation of the $\mathrm{H}$-component called preliminary reverse impulse (PRI) with a time scale of less than a few minutes. The PRI appears in both the afternoon sector of high latitudes and the dayside equatorial region (e.g., Araki, 1977). The PRI is due to the dusk-to-dawn ionospheric electric field carried to the polar ionosphere by field-aligned currents (FACs), which are generated inside the magnetopause by transverse Alfvén waves converted from the compressional hydromagnetic (HM) wavefront (Tamao, 1964). The penetrated electric field transmits to the low-latitude and equatorial ionosphere instantaneously by a TM mode (Kikuchi et al., 1978; Kikuchi and Araki, 1979). During the MI phase, the dawn-to-dusk electric field is penetrated into the polar ionosphere and transmits simultaneously into the low-latitude

Manuscript received on 27 November 2007; accepted on 20 December 2007

* Department of Earth and Planetary Sciences, Graduate School of Sciences, Kyushu University, 6-10-1 Hakozaki, Higashi-ku, Fukuoka, 812-8581, JAPAN ; a-ikeda@geo.kyushu-u.ac.jp

** Space Environ Research Center, Kyushu University, 6-10-1 Hakozaki, Higashi-ku, Fukuoka, 812-8581, JAPAN

*** National Institute of Information and Communications Technology, 4-2-1 Nukiikita-machi, Koganei, 184-8795, JAPAN

**** Department of Earth and Planetary Sciences, Faculty of Sciences, Kyushu University , 6-10-1 Hakozaki, Higashi-ku, Fukuoka, 812-8581, JAPAN

***** Solar-Terrestrial Environment Laboratory, Nagoya University, Furoucho, Chikusa-ku, Nagoya, 464-8601, JAPAN 
Akihiro Ikeda, Kiyohumi Yumoto, Manabu Shinohara,

Kenro Nozaki, Akimasa Yoshikawa and Atsuki Shinbori

ionosphere as in the PRI case. This electric field is due to the enhanced magnetospheric convection in the inner magnetosphere associated with the compression of the magnetosphere (Araki, 1994).

Based on high-frequency Doppler measurements of the ionosphere, SC has been studied (e.g., Anjaneyulu, 2007; Sastri, 2001). At low latitudes, Kikuchi $(1985,1986)$ showed that the preliminary frequency deviation (PFD) caused by the dusk-to-dawn electric field occurs simultaneously with high-latitude PRI, while the subsequent main frequency deviation (MFD) caused by the dawn-todusk electric field occurs simultaneously with MI. However, the intensity of the SC-associated electric fields in the low-latitude ionosphere is not yet studied sufficiently from HF radar observation.

An FM-CW (Frequency Modulated Continuous Wave) radar is one kind of HF (High Frequency) radar and using it for Doppler observation was first put to practical use by Poole (1985) and Poole and Evans (1985). Nozaki and Kikuchi $(1987,1988)$ made improvements to the design. We have installed an FM-CW radar at Station Sasaguri, low-latitude Japan in order to measure the electric fields that penetrate the ionosphere (Yumoto, 2006). Our Doppler observation started in November, 2002. By using the Doppler mode of the FM-CW radar, we can measure vertical drift velocity and virtual height of ionospheric plasmas with high time resolution. Therefore, we can estimate the intensity of the ionospheric electric fields by the method described in Section 2 of this paper. Furthermore, the altitude information enables us to confirm whether or not the observed ionosphere is F-region. In this study, we will show the electric field intensity at the time of the MI phase of SC observed by our FM-CW radar.

\section{Data set}

The present study is based on the data from our FM-CW radar located in Sasaguri, Fukuoka, Japan (Magnetic Latitude: 23.2 ${ }^{\circ}$, Magnetic Longitude: $199.6^{\circ}$ ) with time resolution of 10 seconds. Figure 1 shows our FM-CW radar system which consists of transmitter, receiver and control PC, and Fig. 2 shows a 26 meter antenna tower of the radar. The FM-CW radar is a type of HF radar and can measure the range of target as well as its Doppler related information. This application of the FMCW radar is a variation of a technique developed by Barrick (1973) to measure sea scatter.

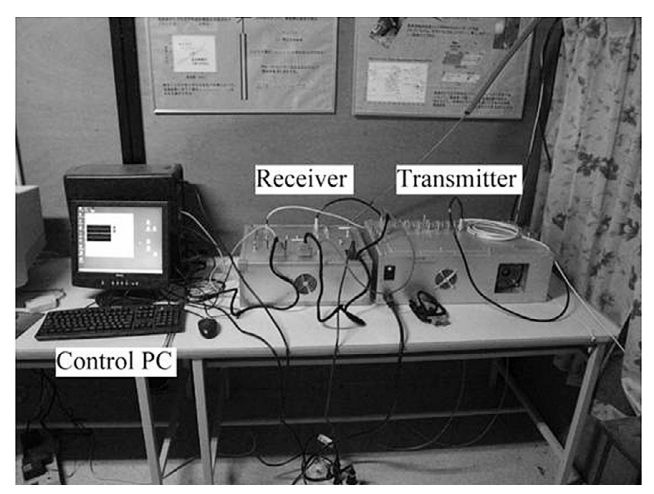

Fig. 1. FM-CW radar system at Station Sasaguri. 


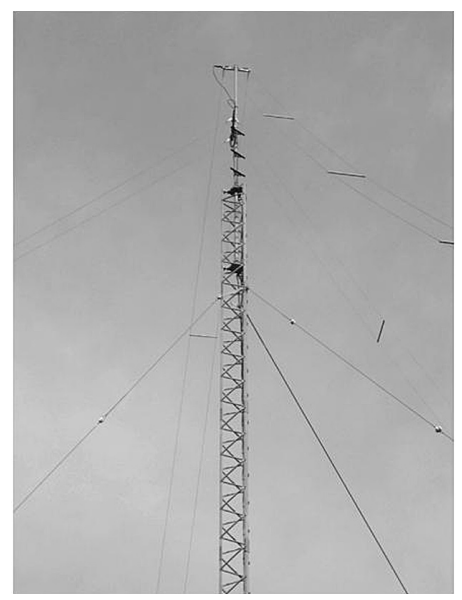

Fig. 2. Tower of an FM-CW radar built at Station Sasaguri.

With our radar system, we are able to measure the vertical drift velocity of the F-region of the ionosphere and its virtual height. When the eastward electric field penetrates into the low-latitude ionosphere, it drifts upward owing to the frozen-in effects $(\mathbf{E} \times \mathbf{B}$ effects) of the F-region (Fig. 3). In contrast to the penetration of the eastward electric field, the ionosphere drifts downward when the westward electric field penetrates. The observed Doppler frequency $\Delta \mathrm{f}$ is the difference between the transmitting frequency ( $\left.\mathrm{f}_{0}\right)$ and the receiving frequency $\left(\mathrm{f}_{0}+\Delta \mathrm{f}\right)$ because of the Doppler effect responsible for the vertical movement of the ionosphere. The relational expression of $\Delta \mathrm{f}$ and $\mathrm{f} 0$ is represented by $\Delta \mathrm{f}=\mathrm{f}_{0} \times 2 \mathrm{v} / \mathrm{c}$, where $\mathrm{v}$ is vertical drift velocity, and $\mathrm{c}$ is the velocity of light. Generally we use $8.0 \mathrm{MHz}$ in daytime and $2.5 \mathrm{MHz}$ in nighttime for the transmitting frequency fo, because of the day and night variations of the ionospheric plasma density. From the above relational expression, the vertical drift velocity $\mathrm{v}$ of the ionosphere is given. The accuracy of the vertical drift velocity is $1.5 \mathrm{~m} \mathrm{~s}^{-1}$ by $8.0 \mathrm{MHz}$ and $4.7 \mathrm{~m} \mathrm{~s}^{-1}$ by $2.5 \mathrm{MHz}$.

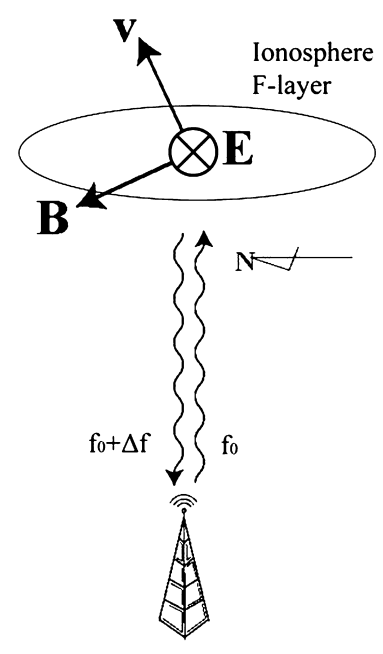

Fig. 3. Schematic picture of the $\mathbf{E} \times \mathbf{B}$ effects of the ionospheric F-region. When the eastward electric field penetrates into the low-latitude ionosphere, it drifts upward. 
In addition, we are trying to calculate $\mathbf{E}$ of $\mathbf{E}=-\mathbf{v} \times \mathbf{B}$, where $\mathbf{E}$ is east-west electric field of the F-region, $\mathbf{v}$ is vertical drift speed, and $\mathbf{B}$ is the magnetic H-component at Sasaguri. This $\mathbf{B}$ is derived using the IGRF model provided from World Data Center for Geomagnetism, Kyoto (http://swdcwww.kugi.kyoto-u.ac.jp/index.html), which requires two inputs: (1) the altitude of the Fregion (in this case, given by our radar), and (2) the geographical coordinates of Sasaguri given by GPS system.

Moreover, in order to detect the onset time of SC, we use 3 seconds averaged data from magnetometer at Station Kuju (KUJ; M. Lat. 23.6 , M. Lon. 203.2 ${ }^{\circ}$ ). Station KUJ is located about $100 \mathrm{~km}$ southeastward from Sasaguri. This magnetometer station is a part of the Circum-pan Pacific Magnetometer Network (Yumoto and the CPMN Group, 2001).

\section{Data Analysis}

\subsection{Daytime SC on November 4, 2003}

Figure 4 shows a geomagnetic field variation of the H-component at Station KUJ and the Doppler frequency measured at Station Sasaguri on November 4, 2003. The time interval is 15 minutes from 06:20 to 06:35 (UT) corresponding to the afternoon local time. When the westward electric field penetrates into the ionosphere at Station Sasaguri, the ionospheric plasma drifts downward and the Doppler frequency deviates positively. On the other hand, when the eastward electric field penetrates, the Doppler frequency deviates negatively. The SC onset at 06:26 UT (15:26 LT) is indicated by the vertical dashed line in Fig. 4. After the SC onset, an abrupt decrease of the Doppler frequency occurs with correspondence to an increase of the $\mathrm{H}$-component. Therefore, this negative deviation is an MFD. Moreover, this MFD was preceded by a small increase in the Doppler frequency, which is identified as a PFD. This increase almost coincides with PRI at Station KUJ. The initial peak-to-peak change of the MFD is $-1.29 \mathrm{~Hz}$, and from this value we estimate the electric field intensity (hereafter, we call this electric field the MFD-electric field) as $0.69 \mathrm{mV} \mathrm{m}^{-1}$ (eastward). During this $\mathrm{SC}$ event, the radar transmitting frequency was $8.0 \mathrm{MHz}$ and the observed ionospheric altitude was about $260 \mathrm{~km}$ (virtual height).

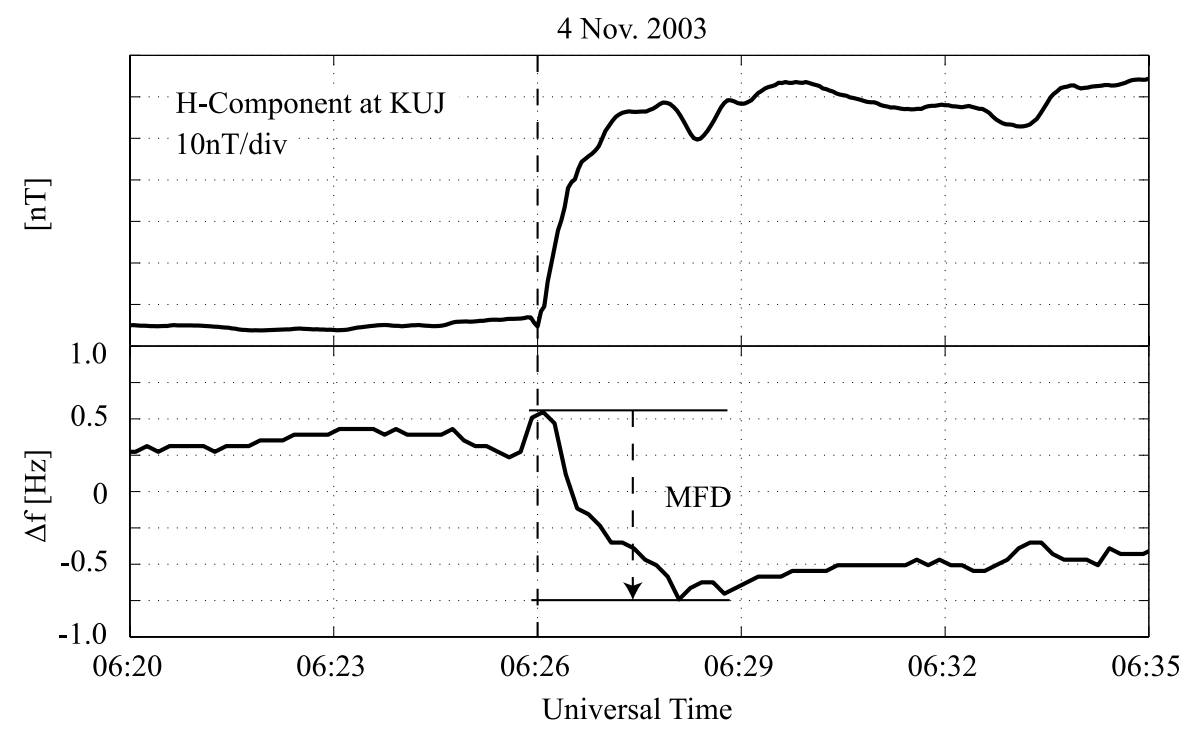

Fig. 4. SC at daytime on November 4, 2003. The upper panel shows the geomagnetic H-component at Station KUJ and the bottom panel shows the Doppler frequency $\Delta$ f observed at Station Sasaguri. 


\subsection{Nighttime SC on January 21, 2005}

Figure 5 shows plots of the nighttime SC observed at 17:12 UT (02:12 LT), on January 21, 2005. The format of this figure is the same as that of Fig. 4. The transmitting frequency of the FM$\mathrm{CW}$ radar was $2.5 \mathrm{MHz}$ during this $\mathrm{SC}$ event and the observed ionospheric altitude was about 360 $\mathrm{km}$ (virtual height). In contrast to the case of daytime (Fig. 4), the MFD is a positive deviation, and the precedent PFD is a negative deviation. The initial peak-to-peak change of the MFD is $0.70 \mathrm{~Hz}$. From this change, we estimate the MFD-electric field as $1.15 \mathrm{mV} \mathrm{m}^{-1}$ (westward).

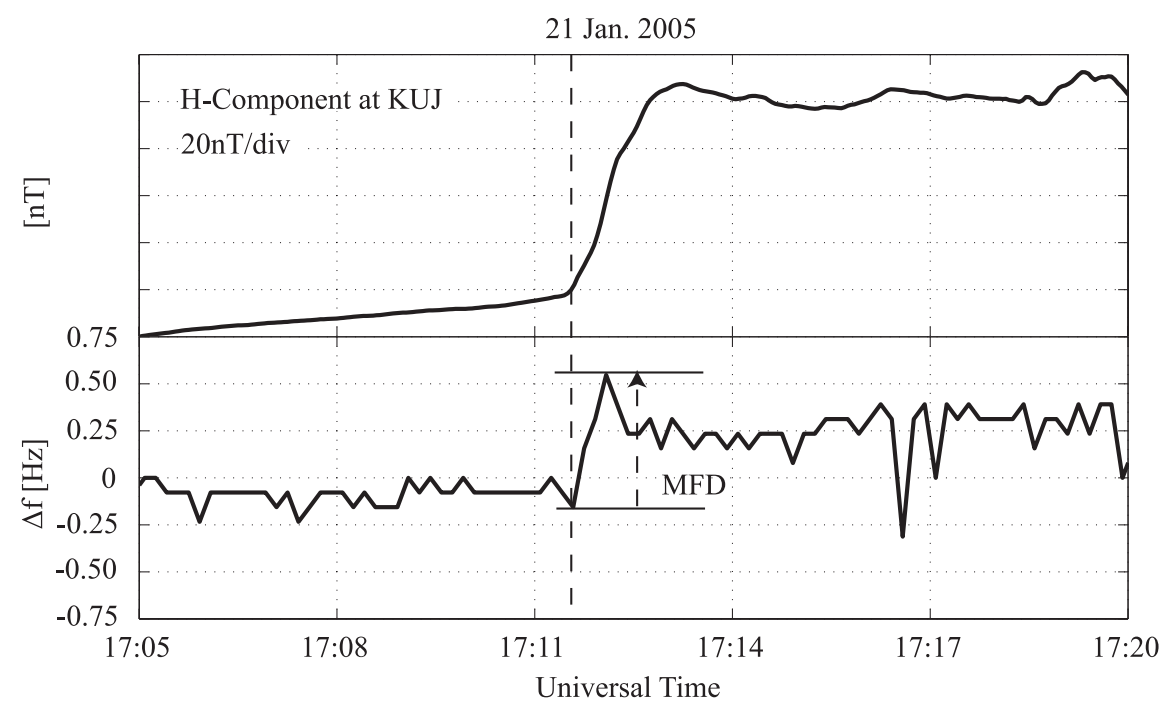

Fig. 5. SC at Nighttime on January 21, 2005. The format of this figure is the same as that of Fig. 4.

\section{Discussion and Conclusion}

We have presented the low-latitude ionospheric electric field during MIs of SCs observed by our FM-CW radar at a low-latitude station. From the electric field observation, we showed clear deviations of the Doppler frequency corresponding to each SC event (see Figs. 4-5). The deviations suggested that a remarkable difference in the PFD and MFD between daytime and nighttime sectors. This difference can be explained by the dusk-to-dawn and the dawn-to-dusk polar electric fields, respectively. This result is consistent with the analyses by Kikuchi et al. $(1985,1986)$.

Further, we estimated the MFD-electric field intensity from the deviations of the Doppler frequency during the MI phase of SC. From our case study, we estimated the MFD-electric field was $0.69 \mathrm{mV} \mathrm{m}^{-1}$ (eastward) in dayside on November 4, 2003. In the case of nightside, MFD-electric field was $1.15 \mathrm{mV} \mathrm{m}^{-1}$ (westward) on January 21, 2005.

We stress that our FM-CW radar system can measure the short-term phenomena through Doppler shift measurements. 
Akihiro Ikeda, Kiyohumi Yumoto, Manabu Shinohara,

Kenro Nozaki, Akimasa Yoshikawa and Atsuki Shinbori

\section{Acknowledgments}

We would like to thank Mr. Ryuichi Ishihara, Mr. Kazuhiro Mori and Mr. Toshiki Shinbaru for helping to construct our FM-CW radar system. We also acknowledge critical comments provided by the reviewer. The author (A. Ikeda) is supported by Professor Tatsuro Matsumoto Scholarship Fund. One co-author (A. Shinbori) is also supported by a grant of Research Fellowship of the Japan Society for the Promotion of Science for Young Scientists. The work for this paper was supported by JSPS as the Grant-in Aid for Overseas Scientific Survey (15253005) and in part by NICT (the National Institute of Information and Communications Technology).

\section{References}

Anjaneyulu, P., Lakshmana Das, N., Rao, B. M., and Ramakrishila, C. (2007) Low-latitude HF Doppler short-period oscillations associated with storm sudden commencements, Current Science 92 (4), 502-506.

Araki, T. (1977) Global structure of geomagnetic sudden commencements, Planet. Space Sci., 25, 373-384.

Araki, T. (1994) A physical model of the geomagnetic sudden commencement, in Solar Wind Sources of Magnetospheric Ultra-Low-Frequency Waves, Geophys. Monogr. Ser., vol. 81, edited by M. J. Engebretson et al., AGU, Washington, D. C, 183-200.

Barrick, D. E. (1973) FM-CW Radar Signals and Digital Processing, NOAA Technical Report ERL, 283-WPL 26.

Kikuchi, T., and Araki, T. (1979) Transient response of uniform ionosphere and preliminary reverse impulse of geomagnetic storm sudden commencement, J. Atmos. Terr. Phys., 41, 917-925.

Kikuchi, T., Ishimine, T., and Sugiuchi, H. (1985) Local time distribution of HF Doppler frequency deviations associated with storm sudden commencements, J. Geophys. Res., 90, 4389.

Kikuchi, T. (1986) Evidence of transmission of polar electric fields to the low latitude at times of geomagnetic sudden commencements, J. Geophys. Res., 91, 3101.

Nozaki, K., and Kikuchi, T. (1987) A new multimode FM/CW ionosonde, Mem. Natl Inst. Polar Res., Spec. Issue, 47, 217-224.

Nozaki K., and Kikuchi, T. (1988) Preliminary results of the multimode FM/CW ionosonde experiment, Proc. NIPR Symp. Upper Atmos. Phys., 1, 204-229.

Poole, A.W.V. (1985) Advanced sounding 1. The FMCW alternative, Radio Sci., 20, 1609.

Poole, A.W.V., and Evans, G.P. (1985) Advanced sounding 2. First results from an advanced chirp ionosonde, Radio Sci., 20, 1617.

Sastri, J. H., Takeuchi, T., Araki, T., Yumoto, K., Tsunomura, S., Tachihara ,H., Luehr, H., and Watermann, J. (2001) Preliminary impulse of the geomagnetic storm sudden commencement of November 18, 1993, J. Geophys. Res., 106 (A3), 3905-3918.

Tamao, T. (1964) Hydromagnetic interpretation of geomagnetic SSC*, Rep. Ionos. Space Res. Jpn., $18,16-31$.

World Data Center for Geomagnetism, Kyoto (http://swdcwww.kugi.kyoto-u.ac.jp/index.html)

Yumoto, K., and the CPMN Group (2001) Charcteristics of Pi2 magnetic pulsations observed at the CPMN stations: A review of the STEP results, Earth Planets Space., 53, 981-992.

Yumoto, K., and the MAGDAS Group (2006) MAGDAS project and its application for space weather, Solar Influence on the Heliosphere and Earth's Environment: Recent Progress and Prospects, Edited by N. Gopalswamy and A. Bhattachayya, IBN-81-87099- 40-2, 399-405. 